\section{ALL-NATURAL, BIODEGRADABLE BAMBOO BRUSHES}

Woobamboo, the leading bamboo toothbrush brand in the USA, is now available here in the UK. Keen to encourage adults and children to stay on top of their mouth maintenance with regular brushing, their range includes biodegradable and recyclable bamboo brushes and floss for the whole family.

Crafted from all-natural, biodegradable bamboo and with a stylish design, these cleaning tools are the perfect antidote to the plastic, unrecyclable and often garishly coloured toothbrushes shoppers will find in most supermarkets and pharmacies.

Not only will patients be getting a deep clean thanks to the highquality dental grade bristles, they will also be contributing to the conservation of the planet by reducing plastic waste and opting for and
The bamboo brushes are made from moso bamboo (not the kind that pandas eat!), which is organically-grown in the mountains of China, and crafted in a family-owned workshop, further enhancing the brand's commitment to sustainability and conservation.

Other products that the brand sells include kids' toothbrushes, pet products, and their very own range of eco-awesome biodegradable floss, which is coated in natural wax and crafted in Italy.

Eager to ensure their whole line remains eco-conscious, every single product comes packaged in recycled and recyclable materials including soy based ink for printing. The dental floss has an ingenious design so that the packaging converts into its own dispenser, further reducing plastic waste.

WooBamboo's products are available to purchase at Revital, John Bell \& Croyden, independent health stores, pharmacies, dental clinics and Amazon.

For more information about the product range, visit http://woobamboo.co.uk/. eco-friendly alternative.

\section{TRUE GENIUS}

Oral-B's Genius brush, combined with the Oral-B App, provides the world's most intelligent brushing system, helping users to achieve the best possible at-home dental care.

It does this by combining the best cleaning technology - electric tooth-brushing - with the best guiding technology. Oral-B's oscillatingrotating-pulsating brush-heads provide an outstanding clean, while Oral-B's App makes sure that users brush for the right amount of time, with the right pressure, and that all zones of the mouth are covered evenly. Even the best cleaning and brushing technology in the world cannot help if it isn't applied everywhere evenly.

The position detection capability of the Oral-B Genius is what sets it apart. Other brushes cannot detect where users brush in their mouth as Genius can. Their systems give recommendations on where to brush, but cannot track if indeed the user brushes where their app tells them to do. If the user does not follow the guidance given on the app-screen, their brushes cannot detect where the brush is, and cannot help the user to brush correctly, or to improve their brushing style.

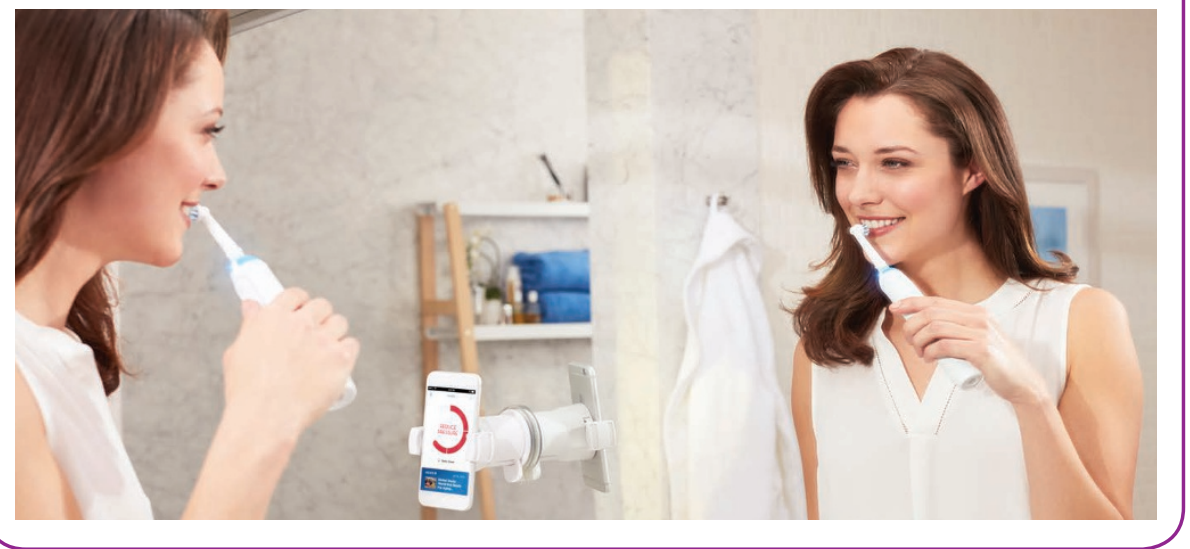

A SUPER-DUPER AUTOCLAVE

Prestige Medical, worldwide

decontamination product specialist, has launched its state-of-the-art autoclave, Advance Pro.

The Blackburn, Lancashire based company, an expert in the development and manufacture of sterilisation equipment, has now added Advance Pro to its extensive portfolio, which also includes the Anima, Visage, PodiaClave+ and Classic range of autoclaves.

The new Advance Pro features the innovative FlexiRack system; a first within the industry, this unique aluminium rack can support 12 individual rails and can be arranged into 20 different configurations.

Another highlight of FlexiRack is the ground-breaking Heat Transfer System, designed and developed to take full advantage of the high performance thermal conductivity properties of aluminium.

The class B steriliser, which includes non-vacuum cycles for maximum flexibility, is available with either a 16 or 22 litre capacity chamber and its compact style is ideal for worktops where space is limited.

Further enhancements include easy to use push button operation, backlit LCD display and pressure die cast door, with stainless steel reinforced Teflon coating, and easy change gasket system.

For more information on the Advance Pro contact sales@prestigemedical. co.uk or call 01254844103.

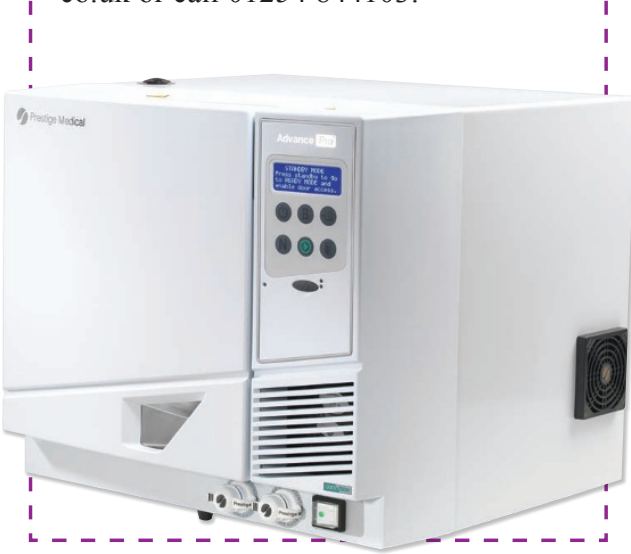

If you would like to promote your products or services direct to the dental industry in BDJ Team, call Andy May on 02078434785 or emaila.may@nature.com. 